\title{
The Design and Idea of Cross-cultural Distance Collaborative Learning and Its Enlightenment ${ }^{*}$
}

\author{
Cui Bai Li \\ College of Elementary Education, Hainan Normal University, Haikou,Hainan,China( 571158) \\ 405900956@qq.com
}

\begin{abstract}
Keywords: Cross-Cultural; Collaborative Learning; GlobalSchoolNet; International CyberFair; Doors to Diplomacy
\end{abstract}

\begin{abstract}
Through the Internet, collaborative learning gradually across different countries or regions and presents development of Cross-cultural distance collaboration. The excellent distance collaborative learning project has been more and more into the characteristics of globalization. This paper first summarizes overview of current research in cross-cultural distance collaborative learning at home and abroad. Then, the thesis takes the famous global school network (GSN) project as an example, analysis deeply the classic projects of cross-cultural distance collaborative learning (International CyberFair and Doors to Diplomacy ), summarizes the project general situation, project features and design strategy of the cross-cultural distance collaborative learning, thus revealing the value and enlightenment of cross-culture collaborative learning on the digital development of school-based curriculum, Project-based difference learning and other educational applications. In the end, the thesis suggests carrying out cross cultural distance collaborative learning to improving the ability of teachers and students using of English in international cooperation.
\end{abstract}

\section{Introduction}

In the information age, education is becoming more and more networking, collaboration, internationalization. Cross-cultural online collaborative learning is collaborative learning in network and communication activities between the different regions (countries), the national culture through the development of the internet. Cross cultural distance collaborative learning pay attention to the different cultural backgrounds, relates to language communication, social custom, social psychology, values and so on, which cross-cultural communication is as the main characteristics of the mode of learning.

Review of Cross cultural distance collaborative learning situation at home and abroad. In recent years, the domestic primary and secondary schools have accumulated a number of Intercollegiate distance collaborative learning organization experience (such as: Wu Bingjian teacher organization of primary school English teaching internet exchange program, Professor Xu Xiaodong Organization collaborative learning task, the central Dianjiaoguan sister school program), but rarely carry out cross cultural distance collaborative learning scale. Relatively speaking, the overseas from twentieth Century 80 time to carry out distance collaborative learning has gradually formed a lot of global distance collaborative learning project, which has the representative: Global School Network (GSN), Norway Kindlink, iEARN, Think remote cooperative learning, ThinkQuest (global student website making competition) etc.. These global distance collaborative learning project organization of large scale, long duration, multinational users, the platform function is strong, has the characteristics of cross-cultural learning remote

\footnotetext{
* Foundation Item: Development and Implementation of Digitization of School-Based Curriculum on Global Distance Collaborative Learning Perspective. 2010 Youth Fund Project of Humanities and Social Science Research of Ministry of Education (Project Number: 10YJC880063).
} 
collaboration distinct. According to the cooperation level projects, collaborative learning can be divided into the solution of the basic type for sharing, survey research, (Judi Harris, 2000).

The Design of Cross cultural distance collaborative learning project. Because English is the language barrier, the current domestic schools mainly in domestic school internal web-based collaborative learning, inter school collaborative learning in distance collaborative learning, carry out cross national, cross culture is less. Based on the global distance collaborative learning website project as an example, in-depth analysis of the connotation, cross cultural distance collaborative learning characteristics and design strategy, reveal the design concept and education value of the cross cultural distance collaborative learning, in the hope of learning to provide reference for our country to carry out remote collaboration across cultures.

The General Situation of Global School Network Project . Global School Network (Global School Net, hereinafter referred to as GSN), also known as the global distance collaborative learning network. Global School Network (GSN) as the most influential global distance collaborative learning platform, cross cultural distance collaborative learning project, lasted for a long time. GSN aims to carry out distance collaborative learning, training students with people all over the world communication and cooperation skills, establish the students' understanding of multi culture, cultivate students' global consciousness. GSN website project topics have everything that one expects to find, both diplomacy, international security, terrorism, human rights, global warming and climate change problem in the world, also include exploration of local characteristics, food culture, folk customs and other cultural projects, moreover also relates to the exploration space, waste management, innovative ways of network security research of science and technology issues, often a project involving multiple disciplines knowledge synthesis. As of 2014 December, GSN website has brought together 2651 distance learning project, there are more than 20 ongoing projects, involving almost all types of cross-cultural collaborative learning, fully embodies the various disciplines of distance collaborative learning subject in primary and secondary schools.

International CyberFair and Doors to Diplomacy Project. In the GSN project, the projects of International CyberFair and Doors to Diplomacy are the most famous website contest of the project. These two projects are almost every year since its creation, in competition of project driven cross cultural distance collaborative learning, project planning, publicity, organization and evaluation has a set of complete and comprehensive program of activities, thus attracting the attention of many countries around the world to participate in school. International CyberFair focused on the theme of local cultural characteristics, from 1996 started to 2015, has been held for 20 years, has for many years been tens of thousands of more than thousands of schools from more than 100 countries students to participate in, is the world's largest certified web design competition. Doors to Diplomacy cares international affairs and global diplomacy as the breakthrough point, there are a lot of new members to join them a year. On the comparison of the two, as shown in the Figure 1.

\begin{tabular}{|l|l|l|}
\hline \multicolumn{1}{|c|}{ International CyberFair } & \multicolumn{1}{|c|}{ Doors to Diplomacy } \\
\hline website & www.globalschoolnet.org/gsncf/ & www.globalschoolnet.org/gsndoors/ \\
\hline project focus & The local community characteristics & Global diplomacy \\
\hline classic case & $\begin{array}{l}\text { A Man of Change: Innovator of the } \\
\text { Youth 、 Special Needs } \\
\text { Children 、 Coding the Future 、 } \\
\text { Lanzhou Sheepskin Rafts }\end{array}$ & $\begin{array}{l}\text { A Doorway to the Riches of } \\
\text { Turkmenistan、Diplomacy, Art, and Culture } \\
\text { Global Humanities V Haiti Ocean Project } \\
\text { Leaders of Leaders }\end{array}$ \\
\hline
\end{tabular}

Figure. 1 the Difference of International CyberFair and Doors to Diplomacy 


\section{The design strategies of cross cultural distance collaborative learning project}

Cross cultural distance collaborative learning focuses on cultivating students' intercultural communication competence and international understanding ability, encourage students' development of globalization in the task in the process of problem solving ability, has the following characteristics of the project design.

The Depth of Integration of Local Research and Digital Learning. Cultural differences, cross-cultural collaborative learning is the focus of attention, so closely integrate their projects usually manifests for the in-depth research on the local culture and digital learning and communication, emphasizing student team in addition to carry out research on network based project, at the same time to the local community, organization, culture in-depth investigation. For example, in the international Webpage fair and diplomatic doors project, each team must choose one from the eight categories of topic, determine the research topic of their own, using various means of information technology to carry out an in-depth research, discussion, interview record, photography, and a series of activities, and the research results will be made Webpage network exchanges and cooperation, the implementation of the entire process of project reflects the integration of local exploration depth and digital learning.

Pay Attention to Cross Culture Team. Cross cultural distance collaborative learning focus on trans regional team, and put it as a standard evaluation of learning performance. The establishment of research theme, cross-cultural research, and then create the theme website, open network communication, in this long process of teamwork, team members must not only with people from other countries of collaboration, but also to learn from the perspective of global cooperation to solve regional problems. For example, the case "to the gate of Kampuchea" is a group of America students traveling to Kampuchea to carry out the "Citizen Diplomacy" project, the purpose is to research and find the way to solve the problem of school education in rural areas of Kampuchea. Therefore, the students in-depth understanding of the present situation of education in Kampuchea rural schools and an orphanage children living conditions, interviewed 70 of the local rural households, but also went to the capital of Kampuchea and the centre for human rights and human rights experts interview with foreign experts. In the study, some members responsible for the "well" project, to raise funds to solve the problem of water shortage in rural Kampuchea school; some members responsible for the "toilet" project, the construction of the toilet to raise funds for the rural schools in Kampuchea; some members to carry out "the blackboard project" to promote the education of children in rural areas of Kampuchea. Through the project, they not only learn the exchanges and cooperation of cross culture, also the development of the ability of international understanding.

Cultivation of the capability of international communication. Diplomatic doors works entry requirements from the global perspective, to cultivate a global awareness of students and international communication skills, such as: "to the gate of Kampuchea" poor countries pay attention to children's education problems and local human rights; "wild dolphins and manatees" help the global attention of marine ecological problem; "dolphins and manatees" help the global theme activities, the players in order to improve the global youth awareness of marine ecological protection, they joined the Association for the protection of whales and dolphins (WDCS), and become the relevant protection association partners, to the marine ecological damage serious area to conduct propaganda, to the local student introduces current dolphin and manatees face the threat .

While the topic of International CyberFair is mainly focus on the work from the local community, the team works through the performance of local characteristics, culture, a well-known figure or historical customs and so on, and then developing the network cross - cultural exchange and cooperation. For example, our students "paper-cut artist Zhang Lixue" works, can learn to publicity and promotion of Chinese characteristics of culture and art, can also and students around the world for the exchange of different cultures. And in 2008 won the local industrial and commercial enterprises category of Singapore students "Singapore

Airport: enjoy 
the experience" works, focused on the quality of services and facilities at Singapore Airport and introduction of Singapore, Singapore Tourism to foreign tourists, shopping and Food experience.

Use of Information Technology Meaning. In cross culture in distance collaborative learning, most of the use of various means of information technology and subject integration way of learning, often need information technology teachers and other subject teachers' cooperative guidance. For example, in the" leading to the gate of Kampuchea" case, although belong to the theme of political culture, the research process of osmosis students use a variety of information technology tools, such as: in order to raise funds, the use of the Internet, e-mail send contributions to the initiative, to publish a notice in the tabloids, create posters to publicize their activities; to establish show site, they used the camera shooting photographs, access to video interview with cameras; in addition, in order to promote the communication, PowerPoint will use the photo editing a book; create a web site using DreamWeaver, Flash, Photoshop, using YouTube to publish video.

\section{Enlightenment of Cross Education Culture in Online Collaborative Learning.}

Paying Attention to Local Culture, Developing of Digital School Based Curriculum. Cross cultural distance collaborative learning is usually teachers or school beyond the national curriculum independently developed the learning project, project is usually based on the local culture and the development of digital school-based curriculum, and then carry out cooperation and communication of trans regional, cross culture. In the GSN project, a large number of local culture, integration of information technology and the subject of the project not only embodies the digital transformation of the school-based curriculum, but also provides an important reference for the development of school-based curriculum. At present, China's primary and secondary schools face the curriculum reform problems of school-based curriculum, implementation of developing cross cultural distance collaborative learning, not only can solve the shortage problem of school-based curriculum development, but also an effective way to the development and implementation of school-based curriculum. To encourage our primary and secondary schools to carry out cross cultural distance collaborative learning, is one of the effective ways to promote the digital construction of school-based curriculum.

Based on the Differences of Project Learning, Making Learners Become a Global Perspective Problem Solver. In the cross region cooperation in distance collaborative learning, cultural difference has become the main factor of the learning process, thus causing the different background between the inter school peer mutual inspiration and influence each other and strengthening. In the GSN activity, the students experience since the establishment of the theme, form a team, mutual cooperation, sharing of knowledge, technology and information, carry out practical activities of research and publicity and other series, this is a project based learning(Project-based learning). In particular, GSN is to study globalization shared to point to the educational activities, which advocates the learner changes from the local culture of the "information collector" global "information providers" and "information analysts, students must issue based on the difference of project subject to explore local culture and other culture, the learning process is essentially a study of project based on the difference of. The differences in learning, learning more than the average fusion from the perspective of international understanding of globalization, thus help learners become a global perspective problem solver.

Carrying out Cross Cultural Distance Collaborative Learning, Improving the Ability of Teachers and Students Using of English in International Cooperation. In the cross cultural distance collaborative learning, students involved in different countries and schools together to carry out cooperative learning, although participants nationality, cultural background, age, different beliefs, the participants are able to contribute their knowledge and 
wisdom in the common goal of guidance, work together, share cooperation, mutual aid, which not only enhance the students understanding of different cultures, but also improve the students' ability to use English for international cooperation, this is to improve education of primary and secondary schools teaching in our country the internationalization level has important significance. On the other hand, the difficulty of cross cultural distance collaborative learning is also English communication barriers, improving teachers' English level is so important. In cross-cultural collaborative learning, Improving teachers' ability of bilingual teaching, strengthening teacher's information technology teachers and English teachers' guidance, cooperation, sometimes also can introduce funded and translation agencies, improve the enthusiasm and initiative of the teachers and students use of foreign high-quality educational resources. In a word, the difference of language is an important factor affecting the cross cultural distance collaborative learning to carry out, to improve the teachers' and students' communicative competence in English is the key of cross cultural distance collaborative learning.

\section{Summary}

Based on the cross cultural distance collaborative learning, global school network and its classic project (International CyberFair and Doors to Diplomacy) analysis, It the foreign excellent distance collaborative learning project that has been more and more into the characteristics of globalization. In the era of globalization, we should not only actively participate in cross cultural distance collaborative learning, but also to strengthen the cooperation with foreign counterparts, to create a cross cultural distance collaborative learning project.

\section{References}

[1] Zhang Tongle, Culture of Chinese and Western Cultural Differences and Cross Cultural Communicative Ability, Journal of Anhui University of Technology (Social Science Edition).11 ( 2007) 75-77.

[2] Xu Xiaodong, Theory and Educational Value of Interscholastic Collaborative Learning Inspiring by Each other, Research of Education.8(2011) 103-107.

[3] Li Cuibai, Collaborative Networked Learning Community Design , China Educational Technology . 7(2007). 44-47.

[4] Global School Net (GSN).http://www.globalschoolnet.org

[5] Dilireba Liu circle, Kym, Feng Xiaoying, Crown, Review of Collaborative Learning Activities Inpractice , Journal of Distance Education, 3(2007). 72-75.

[6] Xu Yuzhen, Implementation of School based on the National Curriculum , Research and Education. 2 (2008). 53-59.

[7] Dong Ming, Cultural Communication and Intercultural Communication, Application of Language and Words .12(2007).149-153.

[8] Li Cuibai, The integration of information technology and Curriculum , Science Press, Beijing,China . 2014.

[9] Yang Gang, Xu Xiaodong, The science education idea, mode and Its Enlightenment on the online project, China Educational Technology . 9(2010). 15-21. 
[10] Guan Xie,Qian Saiyu, Discussion on the network construction of school-based curriculum model of Regional Alliance, China Educational Technology . 12(2010). 69-72. 